University of Nebraska - Lincoln

DigitalCommons@University of Nebraska - Lincoln

Detection of moniliformin in maize using capillary zone electrophoresis

C. M. Maragos

USDA-ARS-NCAUR, maragocm@ncaur.usda.gov

Follow this and additional works at: https://digitalcommons.unl.edu/usdaarsfacpub

Part of the Agricultural Science Commons

Maragos, C. M., "Detection of moniliformin in maize using capillary zone electrophoresis" (2004). Publications from USDA-ARS / UNL Faculty. 570.

https://digitalcommons.unl.edu/usdaarsfacpub/570

This Article is brought to you for free and open access by the U.S. Department of Agriculture: Agricultural Research Service, Lincoln, Nebraska at DigitalCommons@University of Nebraska - Lincoln. It has been accepted for inclusion in Publications from USDA-ARS / UNL Faculty by an authorized administrator of DigitalCommons@University of Nebraska - Lincoln. 


\section{Detection of moniliformin in maize using capillary zone electrophoresis}

\author{
C. M. Maragos* \\ Mycotoxin Research Unit, USDA-ARS-NCAUR, Peoria, IL 61604, \\ USA
}

(Received 1 March 2004; revised 3 May 2004; accepted 4 May 2004)

Moniliformin is a mycotoxin produced by certain fungi pathogenic to maize. It is capable of causing disease in domestic animals, possibly through inhibition of pyruvate dehydrogenase. Testing for MON commonly involves extraction of maize, isolation of moniliformin using solid-phase extraction columns and detection with high-performance liquid chromatography (HPLC) or gas chromatography. A capillary zone electrophoresisdiode array detection (CZE-DAD) method for determination of moniliformin in maize is reported. The extraction and isolation procedures are similar to those of a commonly used HPLC method, while the detection step requires only $10 \mathrm{~min}$. Sixty-three samples of maize were tested by an established HPLC method using absorbance at $229 \mathrm{~nm}$ (HPLC-ultraviolet light) and by the CZE-DAD method. The limit of detection of the CZE-DAD method was $0.1 \mu \mathrm{g} \mathrm{MONg}^{-1}$ maize compared with $0.05 \mu \mathrm{gg}^{-1}$ for the HPLC-ultraviolet light method. The CZE-DAD method gave good agreement with the HPLC-ultraviolet light method for samples tested at levels up to $1500 \mu \mathrm{g} \mathrm{g}^{-1}$, with a linear regression of $\mathrm{r}^{2}=0.996$.

Keywords: moniliformin, mycotoxin, capillary electrophoresis, detection

\section{Introduction}

Moniliformin (MON) is a mycotoxin produced by several Fusarium species, including the important

\footnotetext{
* To whom correspondence should be addressed.

e-mail: maragocm@ncaur.usda.gov
}

pathogens $F$. proliferatum and $F$. subglutinans. MON, 3-hydroxycyclobut-3-ene-1,2-dione (figure 1) was first reported as a toxin in 1973 (Cole et al. 1973, Springer et al. 1974). It is an acid, with $p K_{\mathrm{a}}=1.70$ (Steyn et al. 1978), and is usually isolated as the sodium or potassium salt. While MON is toxic to both plants and animals, it has not been causally associated with human or animal disease. In animals, MON acts by binding to the mitochondrial pyruvate dehydrogenase complex, perhaps through a suicide inactivator mechanism (Hofmeyr et al. 1979, Gathercole et al. 1986). The resultant disruption of the tricarboxylic acid cycle may cause disruption of oxidative phosphorylation. MON is acutely toxic, with susceptibility varying by species. Among the more sensitive species are cockerels, chickens and ducklings, where the median lethal dose ranged from 3.7 to $5.4 \mathrm{mg} \mathrm{kg}^{-1}$ body weight (Cole et al. 1973 , Kriek et al. 1977, Burmeister et al. 1980). In poultry, MON has a cardiotoxic effect. Fusarium fujikuroi culture material containing MON at levels above $100 \mathrm{mg} \mathrm{kg}^{-1}$ reduced the performance of chicks, including reduced weight gains and feed utilization (Ledoux et al. 1995, Kubena et al. 1997). While MON has been suggested as one of the aetiological factors in Keshan disease in humans, a study of the presence of $\mathrm{MON}$ in grains indicated no significant difference in MON levels in corn or rice from areas with high or low Keshan disease rates ( $\mathrm{Yu}$ et al. 1995). MON was not mutagenic to four tester strains of Salmonella typhimurium (Wehner et al. 1978).
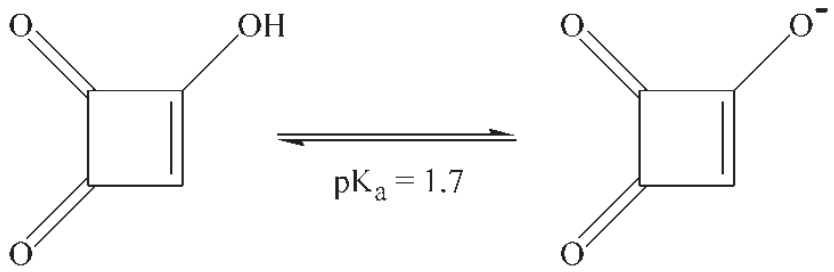

Figure 1. Structures of moniliformin as an acid and as an anion. 
The first report of naturally contaminated maize was from Southern Africa (Thiel et al. 1982), although it has been found on maize, wheat, rye, rice and oats worldwide (Sharman et al. 1991). Prevalence data have been summarized by Munimbazi and Bullerman (2001). MON is highly water soluble, and extraction procedures for MON in cereal grains have generally used either water, water containing an ion-pair reagent, or aqueous mixtures of $80-95 \%$ acetonitrile. Currently there are no antibody-based techniques for detecting MON, perhaps because of the very small size of the molecule (molecular weight of 98 for the free acid). All of the chromatographic methods require a clean up of the cereal extract before the determinative step. The extent of the clean up depends upon the chromatographic method used and the means for detecting the MON. The toxin has absorption maxima at 229 and $260 \mathrm{~nm}$, with molar absorptivities in water of 19100 and 5600 (Steyn et al. 1978). Commonly used methods for the detection of MON include high-performance liquid chromatography (HPLC) methods with ultraviolet light (UV) detection, and gas chromatographic methods using derivatization and mass spectrometric detection (Gilbert et al. 1986, Shepherd and Gilbert 1986, Scott and Lawrence 1987, Thiel 1990, Sharman et al. 1991, Filek et al. 1996, Munimbazi and Bullerman 1998, 2001).

For many analytes, fluorescence detection is preferred due to greater sensitivity or fewer background interferences. The di-carbonyl structure of MON can be derivatized with dichloro-phenylenediamine (also known as diamino-dichlorobenzene, or DDB) to yield a fluorescent product for detection. The fluorescence derivatization has been used after separation of MON by HPLC (Filek and Lindner 1996) or thin-layer chromatography (TLC) (Romer et al. 1997).

Capillary zone electrophoresis (CZE) is an analytical technique where compounds are separated from one another based upon differences in electrical charge. The different separation principle may be useful, particularly for charged molecules such as MON, which is anionic at all but very low pHs (figure 1). Potential advantages of CZE for MON analysis are the elimination of the ion-pair reagent from the determinative step, and more rapid analysis times. Separation of MON by CZE has been reported only twice in the literature (Böhs et al. 1995, Maragos 1998). The first of these reports described the separation of MON from the mycotoxins zearalenone and ochratoxin A (Böhs et al. 1995) within $35 \mathrm{~min}$. The limit of detection for MON was not reported; however, the sensitivity was not as good as that obtained for ochratoxin A $\left(1 \mu \mathrm{g} \mathrm{ml}^{-1}\right.$ at a signalto-noise ratio of 3 ). When $100 \mathrm{ppm}$ solutions of ochratoxin A, MON and zearalenone were tested, the MON peak was roughly one-fifth the size of the ochratoxin A peak. Detection of MON by CE was also reported by Maragos (1998) in a review of the applications of $\mathrm{CE}$ to mycotoxin analysis. In that report, MON was detected within $15 \mathrm{~min}$, and the relatively poor sensitivity of the UV-based detection observed by Böhs et al. (1995) was confirmed.

The goal of the current research was the improvement of the sensitivity of the CE method for MON, so that the technique might be applied to the analysis of maize. Reported here is the first application of CZE to analysis of maize samples for MON. The technique combines a clean-up procedure developed for HPLC (Munimbazi and Bullerman 2001) with CZE with diode array detection (CZE-DAD). Samples of field inoculated maize, containing very low to very high levels of MON, were tested by HPLC with UV detection and CZE-DAD for comparison.

\section{Materials and methods}

\section{Reagents}

Except where noted otherwise, de-ionized water (Nanopure II, Sybron/Barnstead) was used in the preparation of all reagents. All solvents were HPLC grade. MON and tetrabutyl-ammonium hydrogen sulfate (TBAHS) were purchased from Sigma Chemical Co. (St Louis, MO, USA). All other chemicals and solvents were reagent grade or better and purchased from major suppliers.

\section{Sample preparation}

Maize growing on test plots at the National Center for Agricultural Utilization Research (Peoria, IL, USA) was inoculated with several strains of $F$. subglutinans. The maize was allowed to dry in the field 
before harvesting and shelling. Shelled maize was ground with a Stein mill to pass a 20 -mesh screen. Ground maize was extracted and the extracts were purified as described below. Purified extracts were tested by both HPLC and CZE. The identity of the strains and the results relating toxin production to strain identity will be published elsewhere (Dr Anne Desjardins, USDA-ARS, Peoria, IL, USA, personal communication).

The extraction and clean-up procedures were essentially those of Munimbazi and Bullerman (1998), with minor modifications. Ground maize $(20 \mathrm{~g})$ was combined with $100 \mathrm{ml}$ of $1 \%(\mathrm{w} / \mathrm{v})$ TBAHS in water in a $500 \mathrm{ml}$ silane-treated flask. Samples were mixed on a wrist action shaker (Burrell Corporation, Pittsburgh, PA, USA) for $30 \mathrm{~min}$ and the solution filtered through a Whatman \#4 filter (Whatman International Ltd, Maidstone, UK). The solids retained on the filter were extracted a second time with $100 \mathrm{ml}$ TBAHS solution, and the filtered extracts were combined. Of the aqueous solution, $25 \mathrm{ml}$ were extracted twice with 25-ml volumes dichloromethane. The dichloromethane extract was dried at $50^{\circ} \mathrm{C}$ under a stream of nitrogen gas.

The dichloromethane extract was reconstituted with $1 \mathrm{ml}$ water and applied to a Discovery DSC-SAX strong anion exchange column (100 mg sorbent mass; Supelco, Bellefonte, PA, USA) that had been conditioned with successive 1-ml washes of methanol, water, $1 \mathrm{M} o$-phosphoric acid and water. The SAX column was washed with $1 \mathrm{ml}$ water, the remainder of which was expelled from the column. MON was eluted with $1 \mathrm{ml} 0.05 \mathrm{M}$ monobasic sodium phosphate. The purified extract was passed through a 0.2- $\mu \mathrm{m}$ PVDF filter (Acrodisc LC 13, Pall Life Sciences, Ann Arbor, MI, USA). The filtered extract was stored at $4^{\circ} \mathrm{C}$ until tested by HPLC (within 3 days). The extract was then stored at $-20^{\circ} \mathrm{C}$ until tested by CZE. Some of the samples containing very high levels of MON were diluted as much as 100 -fold for testing. To validate the HPLC method in our laboratory, spiking and recovery studies were conducted. Control ground maize containing less than $0.05 \mu \mathrm{g} \mathrm{MON} \mathrm{g}^{-1}$ was spiked with the appropriate volume of a stock solution of $100 \mu \mathrm{g} \mathrm{MON} \mathrm{ml}^{-1}$ in acetonitrile/water $(1+1 \mathrm{v} / \mathrm{v})$, in order to give levels ranging from 0.2 to $5 \mu \mathrm{g} \mathrm{MON} \mathrm{g}{ }^{-1}$ maize. The spiked maize was held overnight at ambient temperature to ensure the spiking solution had dried. The spike samples were then extracted as described above.
HPLC-UV assay

The HPLC system consisted of a Spectra-Physics Model P2000 pump, Rheodyne 7125 injector with $50 \mu 1$ sample loop (Cotati, CA, USA), and a Spectra-Physics Model SP8450 absorbance detector monitoring at $229 \mathrm{~nm}$. For separation a Luna ${ }^{\circledR} 250 \times$ $4.6 \mathrm{~mm}$ i.d., 5- $\mu \mathrm{m} \mathrm{C18(2)} \mathrm{column} \mathrm{(Phenomenex,}$ Torrance, CA, USA) with a NewGuard RP-18 $15 \mathrm{~mm} \times 3 \mathrm{~mm}$ i.d., $7-\mu \mathrm{m}$ guard column (Applied Biosystems, Inc., Foster City, CA, USA) was thermostated at $28^{\circ} \mathrm{C}$ in a Phenomenex model TS- 130 column oven. To minimize the precipitation of buffer salts and the resulting wear on the pump, at the beginning of the day the system was slowly ramped from the storage solvent (methanol) to the mobile phase, which was then allowed to equilibrate for $1 \mathrm{~h}$. For analyses, the mobile phase was an isocratic mixture of $1.14 \mathrm{mg}$ TBAHS ml ${ }^{-1}, 1.07 \mathrm{mg}$ potassium dihydrogen phosphate $\mathrm{ml}^{-1}$ and $12.5 \%(\mathrm{v} / \mathrm{v})$ acetoni-

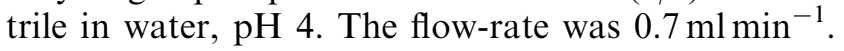
Under these conditions, the retention time for MON was $20 \mathrm{~min}$. Data were collected using Allchrom ${ }^{\text {TM }}$ chromatography data system software (Alltech Associates, Inc., Deerfield, IL, USA). Concentrations of MON in samples were calculated by comparing the response of sample extracts to that of a series of standards over the range $0.125-50 \mu \mathrm{g} \mathrm{MON} \mathrm{ml}^{-1}$ prepared in $0.05 \mathrm{M}$ sodium dihydrogen phosphate. At the end of each day, the system was slowly ramped to $100 \%$ methanol, and the column washed with methanol for $30 \mathrm{~min}$ before storage.

\section{$C Z E-D A D$ assay}

The same extracts from samples tested in the HPLCUV assay were tested in the CZE-DAD assay for comparison. The instrument was a Beckman Coulter P/ACE MDQ capillary electrophoresis system (Beckman Coulter, Fullerton, CA, USA). A fused silica capillary, $75 \mu \mathrm{m}$ i.d., $50 \mathrm{~cm}$ length to detector, $60.2 \mathrm{~cm}$ overall length and thermostated at $27^{\circ} \mathrm{C}$, was used for all experiments. Except where otherwise described, the electrophoresis buffer was $0.15 \mathrm{M}$ phosphoric acid, adjusted to $\mathrm{pH} 2.1$ with $0.15 \mathrm{M}$ sodium dihydrogen phosphate. Before each injection, the capillary was rinsed with electrophoresis buffer for $1 \mathrm{~min}$ at $20 \mathrm{psi}$. The sample or standard was injected by applying $0.5 \mathrm{psi}$ for $20 \mathrm{~s}$. The separation was initiated by the application of a current of $200 \mu \mathrm{A}$ 
(approximately $26.5 \mathrm{kV}$ ). Current was applied in 'reverse polarity' mode, e.g. with the cathode at the inlet and the anode at the outlet. Current was applied for $6 \mathrm{~min}$, then the capillary was rinsed for $1 \mathrm{~min}$ at 20 psi with $0.25 \mathrm{~N}$ sodium hydroxide and for $1 \mathrm{~min}$ at 20 psi with de-ionized water. The diode array detector was set to collect data over the range 190-300 $\mathrm{nm}$ at a rate of $16 \mathrm{~Hz}$. Data were collected using Beckman Coulter 32 Karat software. Including the capillary washes before and after the sample separation, the separation and time required for the autosampler to conduct the necessary manipulations, each sample took $12 \mathrm{~min}$ to analyse. Response of samples was compared with the response of standards prepared in $0.05 \mathrm{M}$ sodium dihydrogen phosphate over the range $1.25-125 \mu \mathrm{g} \mathrm{MON} \mathrm{ml}^{-1}$.

\section{Results and discussion}

Routine analysis of MON in commodities has typically involved extraction of the commodity, purification of the extract using SPE columns, and detection using a chromatographic method (HPLC-UV, TLC or GC-MS). The extraction techniques used have varied depending upon the type of chromatographic method and detection method used. Because MON is strongly anionic, several reported methods have used ion-pair reagents in the extraction step, although extraction without an ion-pair reagent has been reported (Scott and Lawrence 1987, Thiel 1990). The use of tetra- $n$-butylammonium hydroxide (TBAH) as an ion-pair reagent in the aqueous extraction of MON from maize was described by Shepherd and Gilbert (1986). In that paper, the aqueous extract was treated with ion-exchange resin (Amberlite IRC 50), passed through a C18 SPE column, additional TBAH was added, and the resulting extract was partitioned against dichloromethane and dried. Reconstituted extract was separated using reversephase HPLC, and MON was detected by UV absorbance.

Munimbazi and Bullerman $(1998,2001)$ used the ionpair reagent TBAHS in the aqueous extraction of MON from maize. The ion-pair was partitioned into dichloromethane, dried, reconstituted and cleaned-up using a SAX SPE column. MON was eluted from the SPE column with sodium dihydrogen phosphate, separated by reverse-phase HPLC and the absorbance detected at $229 \mathrm{~nm}$.

Several of the reported extraction and clean-up procedures are quite involved. The method of Munimbazi and Bullerman is one of the least cumbersome and was selected as the reference analytical technique for these experiments. Maize inoculated in the field with various strains of $F$. subglutinans was harvested, shelled, ground and then extracted according to the procedure of Munimbazi and Bullerman (2001). The purified extracts, in $0.05 \mathrm{M}$ phosphate buffer, were then tested by HPLC with detection at $229 \mathrm{~nm}$ or CZE-DAD.

To test our proficiency with the reference HPLC method, maize samples were spiked with MON over the range $0.2-5 \mu \mathrm{gg}^{-1}$. Results (table 1) suggest recovery of added MON was good, with an average of $87.8 \%$ being recovered. The reason for the decrease in recovery from $94.9 \%$ at $0.2 \mu \mathrm{gg}^{-1}$ to $80.7 \%$ at $5 \mu \mathrm{gg}^{-1}$ is unknown. It is possible, since the concentration of the ion-pair reagent (TBAHS) is fixed, that at higher MON concentrations the formation of the MON-TBAHS ion-pair is less efficient, leading to less efficient extraction of the MON. Because surveys of MON have found that MON

Table 1. Recovery of moniliformin from spiked maize.

\begin{tabular}{lccc}
\hline $\begin{array}{l}\text { Spiking level } \\
\left(\mu \mathrm{g} \mathrm{g}^{-1}\right)\end{array}$ & Replicate & $\begin{array}{c}\text { Recovery } \\
(\%)\end{array}$ & $\begin{array}{c}\text { Average } \\
\text { recovery } \pm \text { SD }\end{array}$ \\
\hline 0.2 & 1 & 96.6 & $94.9 \pm 4.1$ \\
& 2 & 90.2 & \\
0.5 & 3 & 98.1 & \\
& 1 & 92.7 & $91.8 \pm 1.7$ \\
& 2 & 93.9 & \\
1.0 & 3 & 90.9 & \\
& 4 & 90.0 & \\
& 1 & 88.8 & \\
2.5 & 2 & 88.1 & \\
& 3 & 84.9 & \\
& 1 & 89.4 & \\
5.0 & 2 & 84.7 & \\
& 3 & 74.6 & \\
& 1 & 77.9 & \\
Overall average $(n=16): 87.8 \pm 6.4$ & & \\
\hline
\end{tabular}


occurs infrequently in uninoculated maize at levels greater than $5 \mathrm{\mu g} \mathrm{g}^{-1}$ (Scott and Lawrence 1987, Sharman et al. 1991, Scudamore et al. 1998), this effect is probably not an issue for recovery from uninoculated maize, but may be an issue for highly contaminated samples, inoculated maize or fungal cultures.

In the present authors' laboratory, the limit of detection of the HPLC method was $0.05 \mu \mathrm{g} \mathrm{MON} \mathrm{g}^{-1}$ maize. Samples containing less than this level were classified as 'not detected' and were assigned a value of zero for statistical comparisons. For test samples containing more than $20 \mu \mathrm{g} \mathrm{MONg}^{-1}$, the sample extracts were diluted and re-injected onto the HPLC. The concentrated extracts were stored at $-20^{\circ} \mathrm{C}$ for several weeks until they could be tested by the CZE-DAD method. An experiment where MON standard at a level of $10 \mu \mathrm{g} \mathrm{ml}^{-1}$ was stored at $-20^{\circ} \mathrm{C}$ for 1 week indicated no decrease in signal under these conditions. Replicate injection of extracts from 12 maize samples gave an average coefficient of variation $(\mathrm{CV})$ of $3.08 \%$ and replicate injection of 10 standards gave an average CV of $1.70 \%$.

The clean-up used provided extracts with very few peaks having absorbance at $229 \mathrm{~nm}$, whether the chromatographic method used was HPLC or CZE (figure 2). Results from the two separation and detection methods showed good agreement (figure 3). The data for 63 field-inoculated maize samples covering the range of non-detectable to $1500 \mu \mathrm{g} \mathrm{MON} \mathrm{g}^{-1}$ were fit to the least-squares regression line of: [MON by $\mathrm{CZE}]=0.201+0.897 \times[\mathrm{MON}$ by HPLC $]$, with an $r^{2}=0.996$. This indicates an excellent correlation between the two methods. However, the slope indicates a slight underestimation by CZE-DAD relative to HPLC-UV. The reason for this bias is unknown. Since the same extracts were tested using both methods, it does not derive from the extraction procedure. The magnitude of this effect is not large, and the good correlation with HPLC-UV suggests the CZE-DAD method will be valuable for testing maize for MON.

By comparing the two methods, advantages and disadvantages of each were noted. Because both used the same extraction and clean-up technique, there were no advantages at these steps. The cost of CZE-DAD instruments is generally greater than comparably equipped HPLC-DAD instruments, and fewer laboratories have $\mathrm{CE}$ instrumentation.
Regarding the assays, the CZE-DAD method was more rapid with a migration time for MON of $4.8 \mathrm{~min}$ compared with $20 \mathrm{~min}$ by HPLC. The CZE-DAD method also did not require the inclusion of the ionpair (TBAHS) in the mobile phase: a necessary ingredient in the HPLC mobile phase. This was a significant advantage because the use of TBAHS and phosphate in the HPLC mobile phase required that the solvent delivery lines, pump and columns be slowly equilibrated at the beginning and end of each day to avoid precipitation of the salts during or after clean-up with methanol. Although the retention time of MON on the HPLC was only $20 \mathrm{~min}$, the extended equilibration effectively increased the time required to test each sample well beyond this time. While speed was an advantage of the CZE-DAD method, there were some advantages associated with the HPLC method. The HPLC method was more sensitive (detection limit 0.05 versus $0.1 \mu \mathrm{g} \mathrm{g}^{-1}$ ) and, most noticeably, was less susceptible to changes in the ionic strength of the test solution. Peak broadening can occur with increasing ionic strength in CZE, a common effect that requires using a sample buffer of high enough ionic strength to overcome small changes in the ionic strength of the sample itself. In this work, peak broadening was minimized by the process of sample 'stacking': using an electrophoresis buffer of $150 \mathrm{mM}$ and a sample buffer of $50 \mathrm{mM}$. Given the shorter analysis times and the lack of a requirement for the ion-pair reagent at the determinative step, laboratories having $\mathrm{CE}$ instruments may find benefits to conducting their MON assays using CE-DAD.

\section{Acknowledgement}

The author thanks Mr John Bobell, USDA-ARSNCAUR, for exceptional technical assistance, $\mathrm{Mr}$ Ronald D. Plattner, USDA-ARS-NCAUR, for graciously providing moniliformin, Dr Anne Desjardins, USDA-ARS-NCAUR, for producing and providing the field inoculated maize, and Ms Stephanie Folmar, USDA-ARS-NCAUR, for shelling the inoculated maize. Names are necessary to report factually on available data; however, the USDA neither guarantees nor warrants the standard of the products, and the use of the name by the USDA implies no approval of the product to the exclusion of others that may also be suitable. 
A.

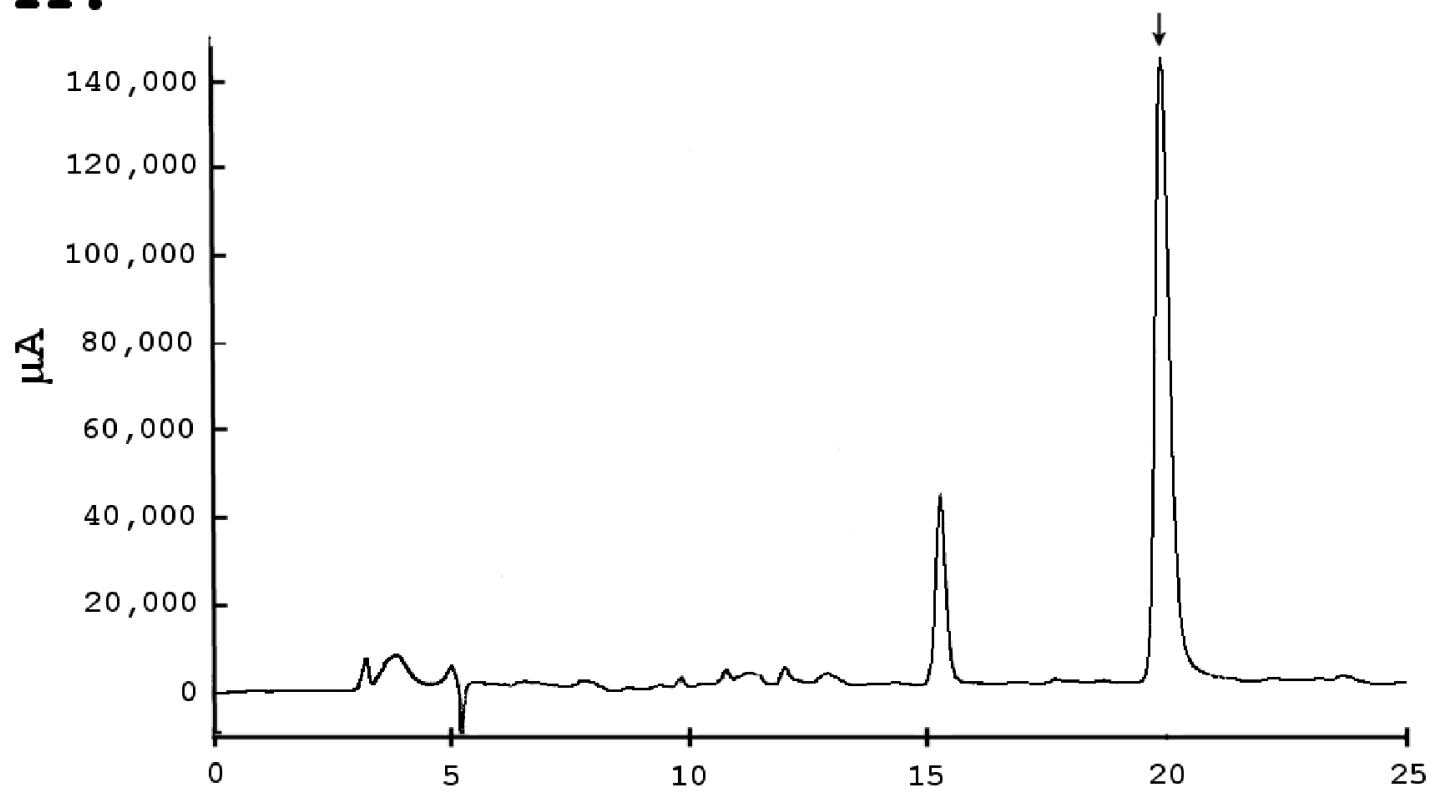

B.

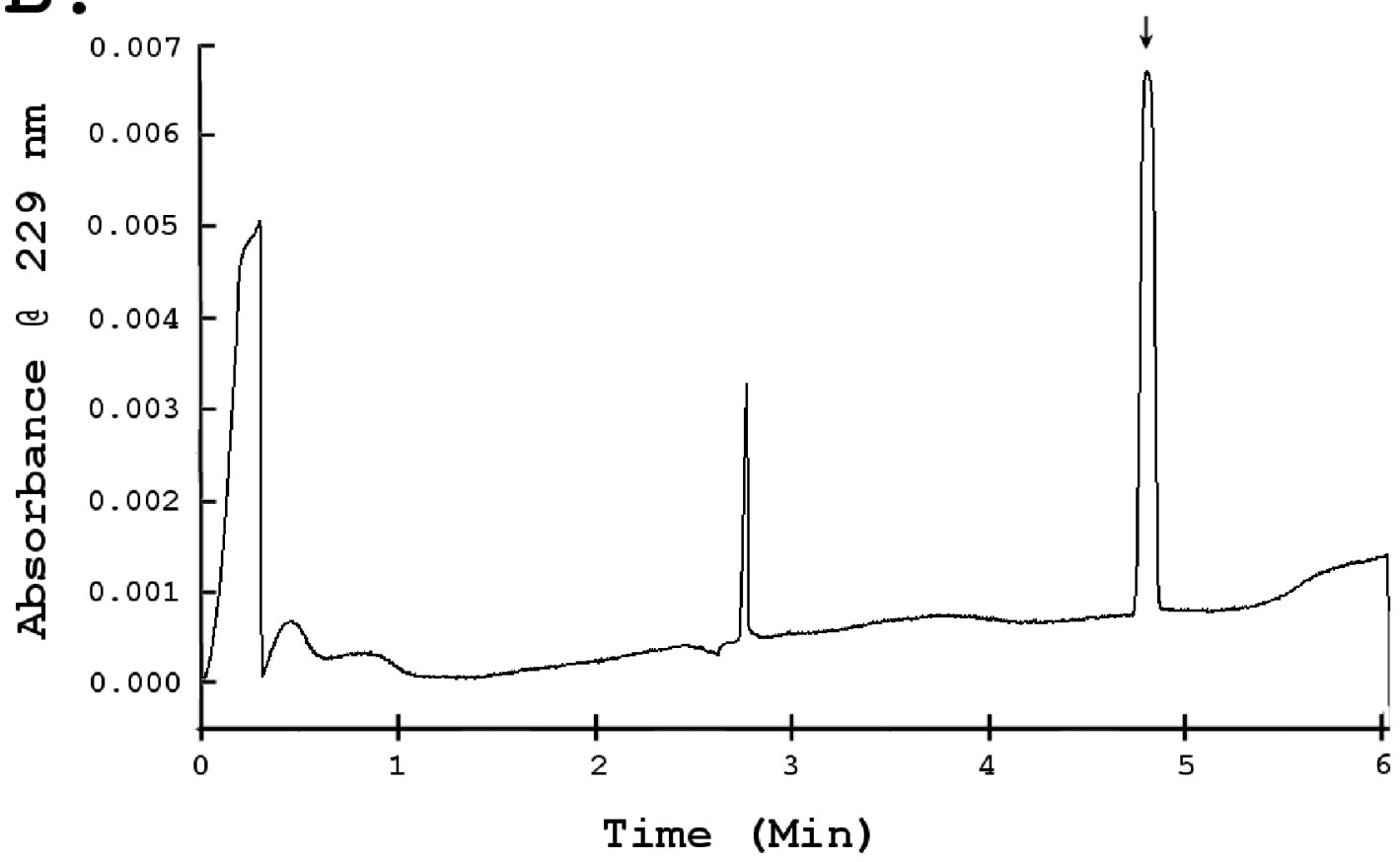

Figure 2. (A) HPLC-UV chromatogram of a maize sample containing $2.8 \mu \mathrm{g} \mathrm{MONg}^{-1}$ and (B) CZE-DAD

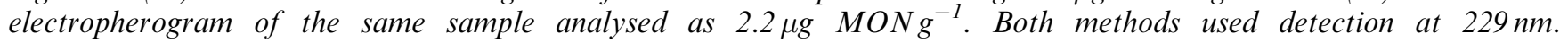
The migration time of $M O N$ is indicated by the arrow. 
A.

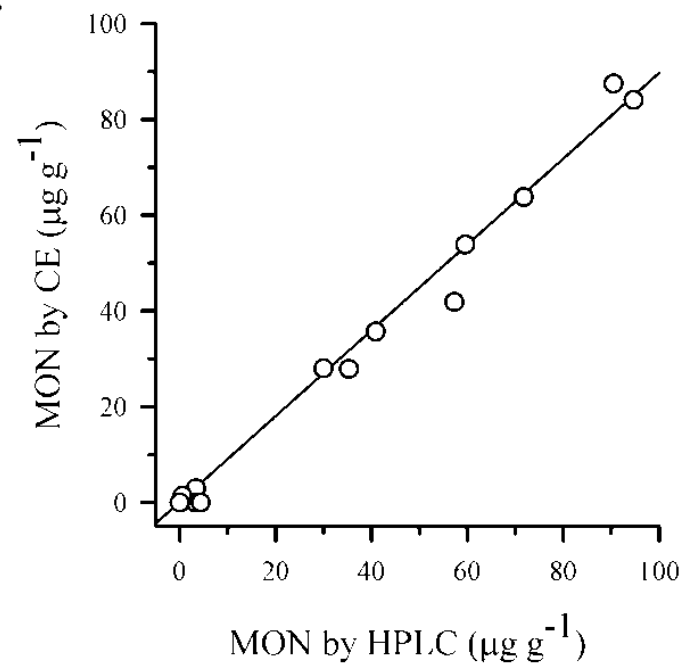

B.

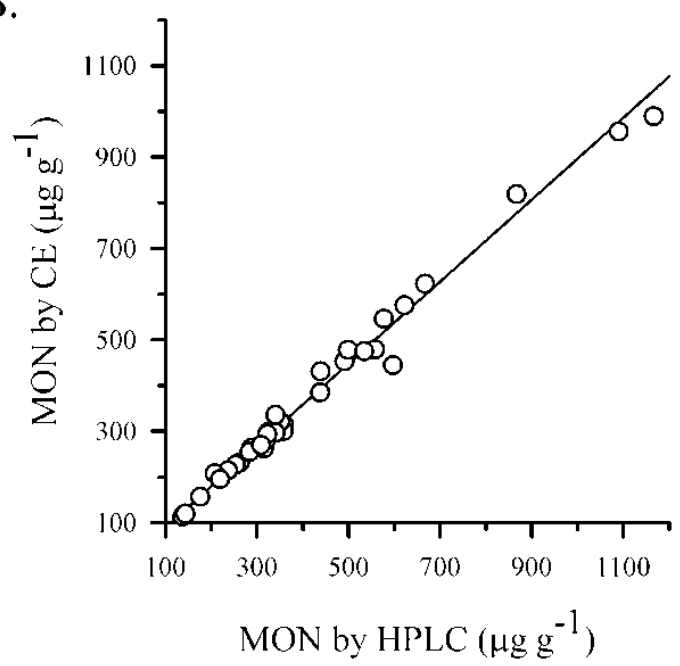

Figure 3. Comparison of HPLC-UV and CZE-DAD for the detection of MON in inoculated maize samples. (A) Comparison for samples containing less than $100 \mu \mathrm{g}$ $\mathrm{MONg}^{-1}$; (B) comparison for samples containing greater than $100 \mu \mathrm{g} \mathrm{MON} \mathrm{g}^{-1}$. Data in both panels have been fit with the regression equation: [MON by $C Z E]=$ $0.201+0.897$ [MON by HPLC], $\mathrm{r}^{2}=0.996$.

\section{References}

BöHs, B., Seidel, V., and Lindner, W., 1995, Analysis of selected mycotoxins by capillary electrophoresis. Chromatographia, 41, 631-637.

Burmeister, H. R., Grove, M. D., and KwoleK, W. F., 1980, Moniliformin and butenolide: effect on mice of high level, long-term oral intake. Applied and Environmental Microbiology, 40, 1142-1144.

Cole, R. J., Kirksey, J. W., Cutler, H. G., Doupnik, B. L., and Peckham, J. C., 1973, Toxin from Fusarium moniliforme: effects on plants and animals. Science, 179, 1324-1326.

FileK, G., and Lindner, W., 1996, Determination of the mycotoxin moniliformin in cereals by high-performance liquid chromatography and fluorescence detection. Journal of Chromatography A, 732, 291-298.

Gathercole, P. S., Thiel, P. G., and Hofmeyr, J. H. S., 1986, Inhibition of pyruvate dehydrogenase complex by moniliformin. Biochemical Journal, 233, 719-723.

Gilbert, J., Startin, J. R., Parker, I., Shepherd, M. J., Mitchell, J. C., and Perkins, M. J., 1986, Derivatization of the Fusarium mycotoxin moniliformin for gas chromatographymass spectrometry analysis. Journal of Chromatography, 369, 408-414.

Hofmeyr, J. H. S., Van der Merwe, K. J., Swart, P., and Thiel, P. G., 1979, Effect of moniliformin on pyruvate dehydrogenase multi-enzyme complex. South African Journal of Science, 75, 469.

Kriek, N. P. J., Marasas, W. F. O., Steyn, P. S., Van Rensburg, S. J., and STEYN, M., 1977, Toxicity of a moniliformin-producing strain of Fusarium moniliforme var. subglutinans isolated from maize. Food and Cosmetic Toxicology, 15, 579-587.

Kubena, L. F., Harvey, R. B., Buckley, S. A., Edrington, T. S., and Rottinghaus, G. E., 1997, Individual and combined effects of moniliformin present in Fusarium fujikuroi culture material and aflatoxin in broiler chicks. Poultry Science, 76, 265-270.

Ledoux, D. R., Bermudez, A. J., Rottinghaus, G. E., Broomhead, J., and Bennett, G. A., 1995, Effects of feeding Fusarium fujikuroi culture material, containing known levels of moniliformin, in young broiler chicks. Poultry Science, 74, 297-305.

Maragos, C., 1998, Analysis of mycotoxins with capillary electrophoresis. Seminars in Food Analysis, 3, 353-373.

Munimbazi, C., and Bullerman, L. B., 1998, High-performance liquid chromatographic method for the determination of moniliformin in corn. Journal of AOAC International, 81, 999-1004.

Munimbazi, C., and Bullerman, L. B., 2001, Chromatographic method for the determination of the mycotoxin moniliformin in corn. Mycotoxin Protocols, edited by M. W. Trucksess and A. E. Pohland (Totowa: Humana), pp. 131-145.

Romer, T., Malone, B., and Brinker, T., 1997, A rapid thin layer chromatographic method for moniliformin. Cereal Research Communications, 25, 385-388.

Scott, P. M., and Lawrence, G. A., 1987, Liquid chromatographic determination and stability of the Fusarium mycotoxin moniliformin in cereal grains. Journal of the Association of Official Analytical Chemists, 70, 850-853.

Scudamore, K. A., Nawaz, S., and Hetmanski, M. T., 1998, Mycotoxins in ingredients of animal feeding stuffs: II. Determination of mycotoxins in maize and maize products. Food Additives and Contaminants, 15, 30-55.

Sharman, M., Gilbert, J., and Chelkowski, J., 1991, A survey of the occurrence of the mycotoxin moniliformin in cereal samples from sources worldwide. Food Additives and Contaminants, 8, 459-466.

ShePherd, M. J., and Gilbert, J., 1986, Method for the analysis in maize of the Fusarium mycotoxin moniliformin employing ion-pairing extraction and high-performance liquid chromatography. Journal of Chromatography, 358, 415-422.

Springer, J. P., Clardy, J., Cole, R. J., Kirksey, J. W., Hill, R. K., CARlson, R. M., and Isidor, J. L., 1974, Structure and 
synthesis of moniliformin, a novel cyclobutane microbial toxin. Journal of the American Chemical Society, 96, 2267-2268.

Steyn, M., Thiel, P. G., and Van Schalkwyk, G. C., 1978, Isolation and purification of moniliformin. Journal of the Association of Official Analytical Chemists, 61, 578-580.

Thiel, P. G., 1990, Determination of moniliformin by highperformance liquid chromatography. Journal of Environmental Pathology, Toxicology, and Oncology, 10, 162-165.

Thiel, P. G., Meyer, C. J., and Marasas, W. F. O., 1982, Natural occurrence of moniliformin together with deoxynivalenol and zearalenone in Transkeian corn. Journal of Agricultural and Food Chemistry, 30, 308-312.

Wehner, F. C., Marasas, W. F. O., and Thiel, P. G., 1978, Lack of mutagenicity to Salmonella typhimurium of some Fusarium mycotoxins. Applied and Environmental Microbiology, 35, 659-662.

Yu, S.-R., Liu, X.-J., WANG, Y.-H., and LiU, J., 1995, A survey of moniliformin contamination in rice and corn from Keshan disease endemic and non-KSD areas in China. Biomedical and Environmental Sciences, 8, 330-334. 